INFLAMMATORY BOWEL DISEASES 1990 
Volume 11

For a list of titles in this series see final page of the volume. 


\section{INFLAMMATORY BOWEL DISEASES 1990}

Proceedings of the Third International Symposium on

Inflammatory Bowel Diseases, Jerusalem, September 10-13, 1989

edited by

D. RACHMILEWITZ

Hadassah University Hospital, Jerusalem, Israel

and

\section{J. ZIMMERMAN}

Hadassah University Hospital,

Jerusalem, Israel 


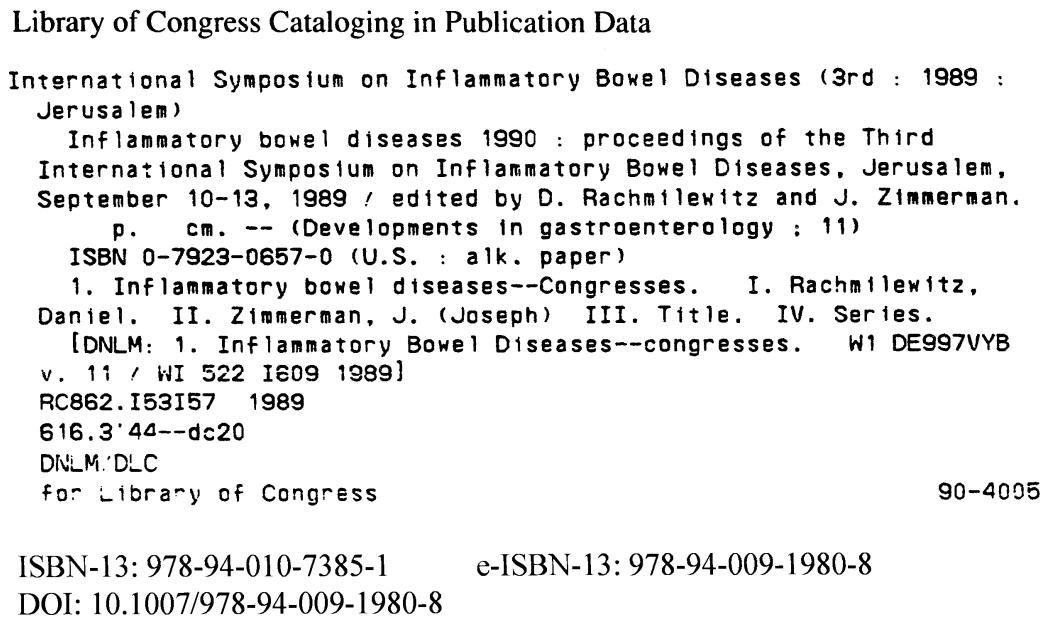

Published by Kluwer Academic Publishers, P.O. Box 17, 3300 AA Dordrecht, The Netherlands.

Kluwer Academic Publishers incorporates the publishing programmes of

D. Reidel, Martinus Nijhoff, Dr W. Junk and MTP Press.

Sold and distributed in the U.S.A. and Canada by Kluwer Academic Publishers,

101 Philip Drive, Norwell, MA 02061, U.S.A.

In all other countries, sold and distributed by Kluwer Academic Publishers Group,

P.O. Box 322, 3300 AH Dordrecht, The Netherlands.

\section{Printed on acid-free paper}
All Rights Reserved
(C) 1990 by Kluwer Academic Publishers
Softcover reprint of the hardcover 1st edition 1990
No part of the material protected by this copyright notice may be reproduced or utilized in any form or by any means, electronic or mechanical including photocopying, recording, or by any information storage and retrieval system, without written permission from the copyright owner. 


\section{CONTENTS}

Preface $\quad$ ix

List of first authors $\quad$ xi

IBD: the present situation and a glimpse of the promised land H.D. Janowitz

Part I : Etiology

Is IBD a genetic disease?

J.I. Rotter, T. Shohat \& C.M. Vadheim 5

Glycoprotein structure and ulcerative colitis

D.K. Podolsky

Barrier function of intestinal epithelial tight junctions (TJ)

J.L. Madara, S. Nash, R. Moore, M. Shapiro, S. Carlson \& C. Delp

Are mycobacteria the cause of Crohn's disease?

W.R. Thayer, Jr.

Smoking and inflammatory bowel disease

M.J.S. Langman

Part II : Pathogenesis and experimental models

Role of platelet activating factor and interleukin I in the pathogenesis of inflammatory bowel disease

D. Rachmilewitz, R. Eliakim, P. Simon, M. Ligumsky \& F. Karmeli

Is there a primary defect in the host defense mechanism in IBD?

C.0. Elson

Evidence against a defect in immune host defenses as a primary process in IBD

L. Mayer

Animal models of inflammatory bowel disease

W.F. Stenson

Part III: Clinical assessment

Why the variation in colitic cancer rates from different centres

R.H. Riddell 
Is there any benefit from cancer surveillance in ulcerative colitis? J.E. Lennard-Jones

Endoscopy in IBD - what has it accomplished?

M.0. Blackstone

The problem of postoperative recurrence of Crohn's disease

D.B. Sachar

Endoscopic examination of the small bowel in idiopathic inflammatory bowel diseases

G.N.J. Tytgat, S.O.P. Hofer, P. Fockens \& M. v. Haastert

\section{Part IV : Nutrition and metabolic implications}

Crohn's disease in children and adolescents : diminished growth velocity T.M. Bayless

Skeletal complications of inflammatory bowel disease

M.D. Sitrin

Enteral nutrition in inflammatory bowel disease

E.G. Seidman, P. Atlan \& C.C. Roy

Total parenteral nutrition in the management of inflammatory bowel

disease: an update

J.B. Mason \& I.H. Rosenberg

Part V : Medical management

5-ASA in ulcerative colitis

S.B. Hanauer

5-ASA preparations in the treatment of inflammatory bowel disease A.B.R. Thomson

4-amino salicylic acid in the treatment of ulcerative colitis: preliminary report of a randomized double-blind placebo controlled trial of oral 4-ASA

A.L. Ginsberg

Olsalazine (Dipentum $\mathbb{B}$ ): the first choice in the treatment of ulcerative colitis

G. Järnerot 
Immunosuppressive drugs: do they have any role in the treatment of IBD? (A)

$$
\text { D.H. Present }
$$

Immunosuppressive drugs: do they have any role in the treatment of IBD? (B)

$$
\text { C.0. Elson }
$$

Cyclosporin in inflammatory bowel disease

$$
\text { D.H. Present }
$$

Use of methotrexate for refractory inflammatory bowel disease R.A. Kozarek

Therapeutic strategies in IBD: Case discussion with computer-aided audience participation

S.B. Hanauer

Index of subjects 


\section{PREFACE}

The Third International Symposium on Inflammatory Bowe1 Diseases was held in Jerusalem during September 10-13, 1989. Four hundred physicians and scientists from 25 countries attended the meeting. The symposium was organized into five panels devoted to state of the art reviews of the latest findings and approaches on the etiology, pathogenesis, metabolic implications, clinical assessment of disease activity and the medical management of IBD. Several issues were discussed in debate form. The last panel was dedicated to discussion of three patients with computer assisted active participation of all the attendants.

In addition, 63 abstracts were presented as posters, a11 of which were published in the Book of Abstracts.

The organizing committee gratefully acknowledges the contributors who presented their work in clear and concise manner and the participants, whose active part in the discussions contributed to the success of the meeting.

The Jerusalem International Symposium on Inflammatory Bowel Diseases has become a tradition that will continue with the Fourth Symposium to be convened in September 1993.

Joseph Zimmerman, M.D.

Danie1 Rachmilewitz, M.D. 
Theodore M. Bayless, Johns Hopkins University

School of Medicine, Baltimore, Maryland.

Michae1 D. Blackstone, University of Chicago, Chicago, I11inois.

Charles 0. E1son, Division of Gastroenterology, The University of Alabama at Birmingham, Birmingham, Alabama.

A11en L. Ginsberg, George Washington University Clinic, 2150 Penn Avenue N.W., Washington DC.

Stephen B. Hanauer, University of Chicago Hospita1, Chicago, Illinois.

Henry Janowitz, 1075 Park Avenue, New York, New York.

Gunnar Jarneröt, Department of Medicine, Orebro Medical Centre Hospital, Orebro, Sweden.

Richard A. Kozarek, Department of Medicine, Virginia Mason Clinic, Seattle, Washington.

Irwin H. Rosenberg, Tufts University, Human Nutrition Research Center, Boston, Massachusetts.

Jerome I. Rotter, Division of Medical Genetics, UCLA Schoo1 of Medicine, Cedars-Sinai Medical Center, Los Angeles, California.
Michae1 J. Langman, Department of Medicine, Queen E1izabeth Hospita1, Birmingham, England.

J.E. Lennard-Jones, St. Mark's Hospital, City Road, London, England.

James Lee Madara, Department of Pathology, Brigham and Women's Hospital, Boston, Massachusetts.

Lloyd F. Mayer, Mount Sinai Hospita1, New York, New York.

Danie1 K. Podolsky, Gastrointestinal Unit, Massachusetts General Hospital, Harvard Medical School, Boston, Maşsachusetts.

Danie1 Present, 12 East 86th Street, New York, New York.

Danie1 Rachmilewitz, Department of Medicine, Hadassah University Hospital, Mount Scopus, Jerusalem, Israel.

Robert Henry Ridde11, Department of Pathology, McMaster University, Hamilton, Ontario.

Michae1 D. Sitrin, Section of Gastroenterology, University of Chicago, Chicago, I11inois.

W. Stenson, Washington University School of Medicine, St. Louis, Missouri. 
xii

David B. Sachar,

Mount Sinai School of Medicine, New York, New York.

F.G. Seidman, Gastroenterology Division, University of Montreal, Ste. Justine Hospital, Montreal, Quebec.

Walter R. Thayer, Rhode Island Hospital, Providence, Rhode Island.
Alan B.R. Thomson, Department of Medicine, University of Alberta, Edmonton, Canada.

Guido N. Tytgat, University of Amsterdam, Academic Medical Centre, Amsterdam, Holland. 